\title{
Writers Camp @ ZSR: Camping, Writing, and Publishing in the Library!
}

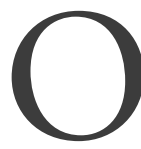
ur story begins in Las Vegas, where a pair of librarians decided to take a chance and roll the dice on a phenomenal outreach opportunity that would attract, inspire, engage, and ultimately connect community members with their library. Of the 41 million individuals who visited Las Vegas in 2014, 18,626 of these visitors were librarians, who had descended upon the city famous for its bright lights, spectacular entertainment, and games of chance for the 2014 American Library Association conference.

For the conference's opening session, organizers invited game designer and author Jane McGonigal to be the keynote speaker. Ms. McGonigal stated that globally there are more than 1 billion gamers (i.e. individuals who spend one or more hours in a day gaming) (Womack, 2014). After sharing findings from research studies on employees feeling disengaged in their jobs and how emotional resilience can be improved through gaming, she suggested constructive gaming could potentially affect challenges facing the world. She posited to attendees, "What if libraries were the place for solving these epic challenges?" (Womack, 2014). McGonigal proceeded to discuss Find the Future, a game that she created in conjunction with the Centennial celebration of the New York Public Library (NYPL). Held overnight inside of the main branch of the NYPL, 500 players, armed with their laptops and smartphones, participated in an interactive game whereby they followed clues to uncover valued library artifacts which would serve as prompts for creative writing projects (New York Public Library, n.d.). The event culminated in the creation and publication of a unique volume of participant essays, which was added to the Library's collection (New York Public Library, n.d.).

Sitting in the opening session's audience were two librarians from the $Z$. Smith Reynolds Library (ZSR) at Wake Forest University (WFU), a private institution located in WinstonSalem, North Carolina. After hearing about McGonigal's Find the Future game, ZSR's Instruction \& Outreach Librarian and the Cataloging Librarian for Nonprint Resources turned to each other and said, "We need to do something like this at our library!" They immediately began discussing which WFU campus constituents they should approach about assisting them in hosting a similar scholarly but fun event at ZSR. Excited about exploring this idea when they returned to work, the two librarians were definitely not going to adhere to the city's famous motto of "What happens in Vegas, stays in Vegas."

ZSR, which is the largest of WFU's three libraries, supports the teaching and scholarly endeavors of both the faculty and students within the University's College of Arts and Sciences, School of Business, Graduate School of Arts and Sciences, and Divinity School. Moreover, ZSR has a successful track record in developing branded programming to promote awareness of faculty and student research to the greater WFU community, and has allowed its $170,000 \mathrm{sq}$. $\mathrm{ft}$. building to be utilized as an additional space on campus in which to host library-sponsored, fun activity programs for students (Burris, McCallum, \& Keener, 2016; Womack, Smith, \& Lock, 2015).

Hearing about the Find the Future game at ALA Annual 2014 inspired the two librarians to transform McGonigal's concept into a similar academically engaging and fun event for WFU students, especially those who enjoy creative writing. They recognized that the planning, organizing, and hosting of such an event would require buy-in and assistance from campus constituents across WFU. They especially wanted the event to generate tangible outcomes not only for ZSR but for the event's participants as well. One potential outcome discussed was the creation and publication of a book of students' writings inspired by University artifacts housed in ZSR's Special Collections and University Archives. The student-authored book would be cataloged and housed in ZSR's general collection and in its Special Collections.

\section{Campus Landscape}

In 2014, a group of ZSR librarians were conducting a yearlong study (designed for the ACRL Assessment in Action program) to identify the success factors that were most important to students. Through survey tools and focus groups, WFU students were asked to rank the importance of several identified success factors categorized under the areas of "Academic Achievement,' 'Academic Engagement,' 'Social and Residential Life,' and 'Life Satisfaction and Development."” 
The study results indicated that academic achievement and obtaining good grades were considered by students to be "their greatest measure of success," whereas "exploring areas outside of [one's] major concentration or interest" -- a success factor categorized under "Academic Engagement" -- received the lowest overall ranking (Z. Smith Reynolds Library, n.d.). Interestingly, the results from the year end surveys, developed by WFU's Office of Institutional Research, ranked "a satisfying social life" as most important by students (Z. Smith Reynolds Library, n.d.). The ZSR research team correlated WFU's first-year students' declining interest in studying abroad, found in the HERI (Higher Education Research Institute) Freshmen Survey of 2014, as additional proof of decreased importance of academic engagement to student success as indicated by students.

This scan of the campus landscape revealed an opportunity for ZSR to develop and offer academically engaging programs for students, complementing ZSR's established repertoire of fun programs and scholarly events. Even more important, such a program would provide "students who seek educational or engaging ways to spend a Friday evening among stimulating like-minded individuals an opportunity to do so...”

\section{Idea Incubation}

After returning from Las Vegas, these two librarians set up an informal meeting of what would later become the core of the Writers Camp Committee. The project's implementation was tabled for a year as the ZSR Library was beginning a search for a new Dean, and more time was needed to allocate necessary resources to ensure the program's success. It was agreed to revisit the idea in Summer 2015 with a plan to host the event in Spring 2016. The
Instruction and Outreach Librarian used this year to develop the project, create a timeline, identify campus partners, and find funding opportunities. The name "Writers Camp @ ZSR", using "Camp" as a verb, was selected to convey the overnight portion of the event.

In Summer 2015, the Words Awake 2 conference was announced. This conference brings alumni authors back to the University to engage with other authors and current students around writing. This was the perfect tie-in to our event, and Writers Camp was announced as part of the lead up to the Words Awake 2 conference. This committed the event coordinators to the timeline to host an event in Spring 2016. At the same time the event was announced, the Instruction and Outreach Librarian was meeting with each campus partner and finalizing the composition of the Writers Camp Committee. The committee consisted of twelve people from six campus partners. There were six representatives from the ZSR Library, two representatives from the Wake Forest Writing Center, and one each from Digital Publishing, the University Press, the Office of Personal and Career Development, and the Words Awake 2 Conference.

Each committee member played an important role in the success of the event. Even before the first complete committee meeting in Summer 2015, conversations with the various constituencies on the committee helped in the development of a project planning document consisting of action items, logistics, required resources, and budget information. These conversations also fostered buy-in to the project. Additionally, discussions with another faculty member on campus, involved in publishing a series of student authored critical media studies, offered insight into the process, informing the committee that the largest single budget item would be the cost of hiring a professional copy-editor for the book.

\section{Pulling It All Together Summer 2015}

By the time the complete Writers Camp Committee met in Summer 2015, there was a project management document, timeline, proposed budget, and initial work had begun on a grant proposal to the Provost's Office to fund the event. The committee agreed on three goals for the program

- Engage students in a fun and scholarly event.

- Showcase Z. Smith Reynolds Library Special Collections.

- Publish a book, catalogued with participants as authors, housed in Special Collections of the Z. Smith Reynolds Library and participate in the Words Awake 2 conference.

Having clear goals was key to the success of the event. As librarians at ZSR have learned, scope creep is real, and without clear goals, it is easy for an event to be co-opted. When changes to the event were proposed, the committee could refer back to these goals to ensure the event stay true to its purpose. After these goals were established, the committee began planning in earnest for an event that was only six months away.

The grant proposal to Provost's Fund for Academic Innovation was completed and submitted, offering three different funding levels for consideration: one that funded the entire event, the cost of the copy editor and the cost of printing the book for the participants; one that removed the copy editor from the budget; and finally, one that removed both the copy editor and the printing of the book. After discussions between the Provost's Office and the grant committee, Writers Camp@ ZSR was fully funded. 
Table 1 Budget for Writers Camp 2016

\begin{tabular}{lrr}
\hline Item & Est. Cost & \multicolumn{1}{c}{ Actual Cost } \\
\hline Marketing: Ad in OGB & $\$ 100.00$ & $\$ 67.50$ \\
Marketing: Coffee Mugs & $\$ 200.00$ & $\$ 322.00$ \\
Afternoon reception--SCA & $\$ 200.00$ & $\$ 102.00$ \\
High quality printing and binding for 5 books & $\$ 500.00$ & $\$ 200.00$ \\
print-on-demand quality printing for $~ 75$ books & $\$ 750.00$ & $\$ 500.00$ \\
coffee and snack to serve during the all-nighter & $\$ 100.00$ & $\$ 45.28$ \\
breakfast (for morning celebration ending event) & $\$ 100.00$ & $\$ 1 /$ \\
Pizza during event & $\$ 150.00$ & $\$ 200.00$ \\
Writing Center tutor hours & $\$ 160.00$ & $\$ 2,000.00$ \\
Copy Editor & $\$ 2,000.00$ & $\$ 3,527.78$ \\
Subtotal & $\$ 4,260$ & $\$ 0.00$ \\
$10 \%$ cushion & $\$ 410$ & $\$ 3,527.78$ \\
\hline Total & $\$ 4,670$ & \\
\hline
\end{tabular}

\section{Fall 2015}

By September, the Writers Camp Committee was hard at work, meeting regularly, assigning and completing tasks, and initial marketing efforts for the event were underway. With grant funding in place, the next challenge was developing a website with all the information and the application process for the writers. The Web Services Librarian created the website, and the Instruction and Outreach Librarian took the lead on gathering and creating the content for the site. Committee members from the Writing Center helped compose the application for Writers Camp, and the committee reviewed the website before it went live.

With the website and event application ready, the committee began marketing the event via social media, flyers, and an ad in the student newspaper. Over the course of a month 41 student applications were received, doubling the number of anticipated participants! Most submitted applications included a writing sample, which was an option on the application, but not a requirement. Interestingly, a wide variety of academic majors were represented in the applicant pool-- including students majoring in Psychology, Art, Politics and International Affairs, Economics, Computer Science, History, Biology, Philosophy, Sociology, French, Communications Studies, and Mathematical Economics. After a group of Writers Camp committee members reviewed the applications and writing samples, the group agreed to accept all 41 applicants. Acceptance emails were shared over the Thanksgiving Break in hopes of creating a more momentous reveal that the student could share with their families. Student authors were asked to commit to the event before the semester break in December.

\section{Spring 2016}

January was a busy month. With only a few weeks before the event, participants were contacted to confirm their participation and share more details about the event, including information on the opening reception and keynote speaker to kick off the event. Librarians attending ALA Midwinter reached out to vendors for schwag for the event. Graduate assistants from the Writing Center were scheduled to work the event, and volunteers were solicited from the Library staff to work part or all of the overnight event.
In the weeks leading up to the inaugural Writers Camp @ ZSR event, there were several tasks to manage and complete. Committee members worked to confirm the attendance of our opening reception guests-- namely, the Wake Forest Demon Deacon, the university's mascot and Jenny Puckett, Wake Forest Alumna, distinguished faculty member, and Wake Forest historian, who gave the opening kickoff address. Like a pep rally before the big game, the opening reception provided an opportunity to cultivate spirit and enthusiasm for the event that resonated with program participants and student writers.

A call for volunteers within ZSR Library was made to invite other library staff that were interested in contributing to, and engaging with, the event. The additional volunteers were available to help with set-up of the event and provide extra assistance with any potential unexpected challenges. Volunteers were also tasked with taking photographs of the program during the event.

The Writers Camp Committee also worked to gather and reserve all required equipment for the event, including public announcement equipment and whiteboards for signage. Program refreshments and materials for the Relaxation Station were also acquired, including catered food for the opening reception, pizzas for a latenight meal, various snacks, coffee and assorted beverages. Writers Camp "schwag bags" were also assembled. These gift bags included various writing supplies (pens, post-it notes), water bottles, and a customized Writers Camp coffee mug.

Arrangements were made for graduate student tutors from the Wake Forest University Writing Center to be on hand and available to assist with any editorial needs that the student writers required during the program. These tutors were compensated from 


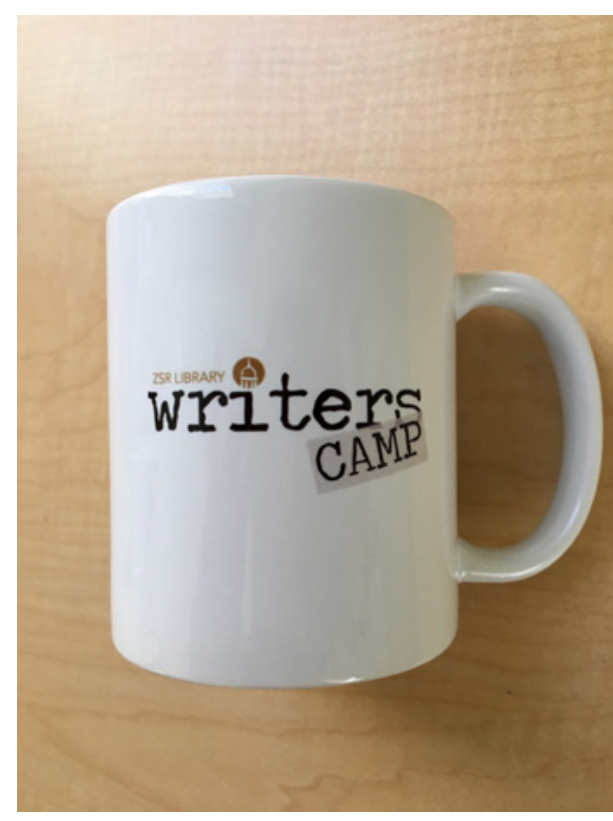

Every student author and Writers Camp committee member received a customized Writers Camp @ ZSR mug.

the Provost grant funding that was awarded for this program. The week before the event, a Google Drive folder was created to hold each of the Writers Camp students' works, which created an easy and accessible way for students to share their work with Writers Camp coordinators, Writing Center tutors, and copy editor for the project.

\section{Day of the Event}

On Friday, January 29th, Writers Camp committee members and student writers were excited to participate in the first ever Writers Camp @ ZSR Library event! The morning and early afternoon allowed program coordinators to double-check all necessary supplies and confirm participation from volunteers. Our pre-planning documents, attention to detail and organized timeline really assisted in keeping everything running smoothly leading up to the start of the program.

At 3:00 pm, the Opening Reception commenced, and Writers Camp student authors and committee members met in the Library's Special Collections Reading Room. Author and distinguished faculty member,

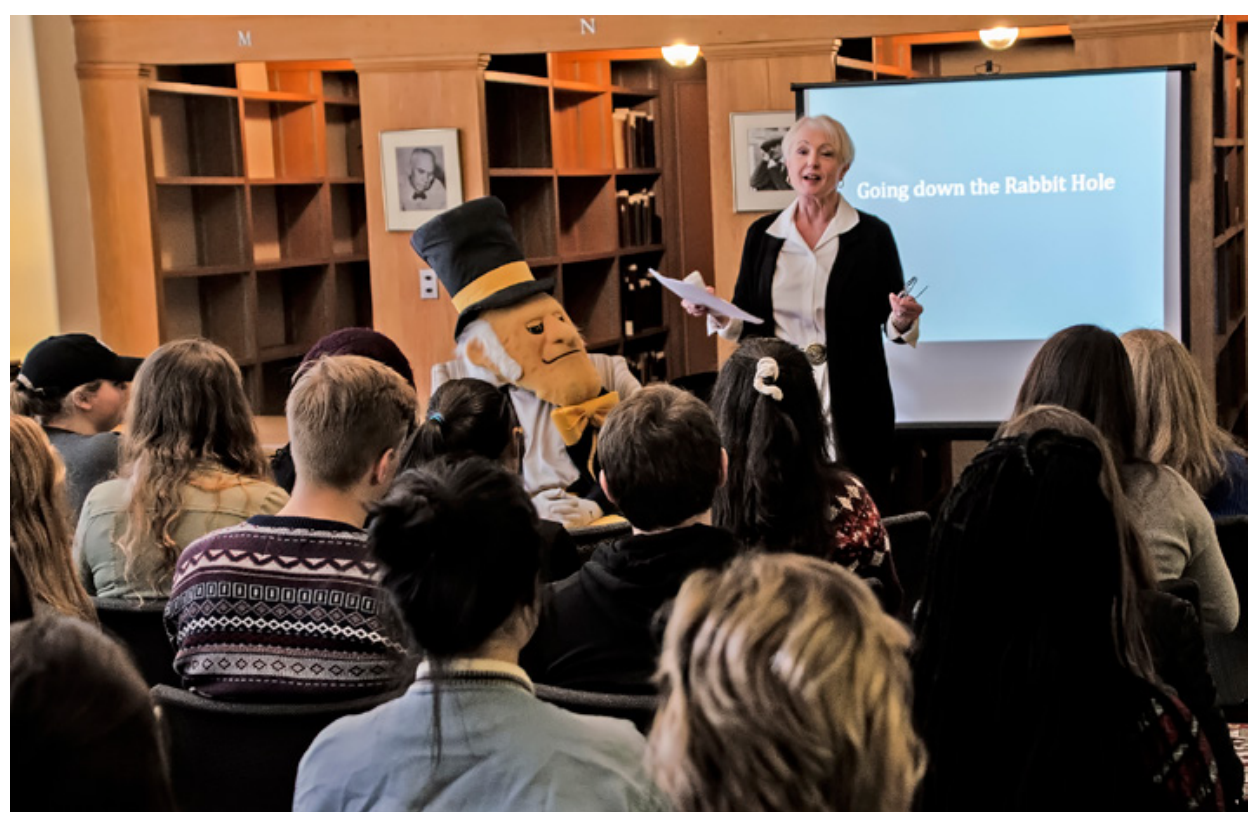

Jenny Puckett, WFU historian and distinguished faculty member, opens Writers Camp 2016 with her presentation, "Going Down the Rabbit Hole" in the ZSR Library's Special Collections Reading Room.

Jenny Puckett, provided a brief presentation entitled "Going Down the Rabbit Hole" to inspire and motivate student authors and the Demon Deacon was on hand to generate enthusiasm.

During this Opening Reception, student authors were matched with their Wake Forest artifact, that would serve as the inspiration for their creative works. After this brief opening reception, student participants were free to adjourn before the program began in earnest at 7:30 pm.

As the student authors returned to ZSR Library on Friday evening, eager for the start of the Writers Camp program, committee members and volunteers were ready for the event to unfold! Program coordinators had spent the previous hour setting up for the event and addressing any last minute arrangements. Since the entire library was open to a select group of students, Writers Camp coordinators chose to implement a robust check-in system to greet each student participant, distribute program gifts and materials, and emphasize expectations for program attendance (we instructed participants to inform one of the program coordinators if they decided to leave at any point). Additionally, an after-hours library chat service-- called the 'Writers Camp Hotline'-- was made available to all campers and remained open during the duration of the event and was monitored by event coordinators.

At 7:00 pm, Dr. Ryan Shirey, Director of the Wake Forest University Writing Center, opened the event with encouraging remarks and seasoned advice to guide the evening's writing experience. This portion of the program was captured and shared on the Library's Instagram channel, and program coordinators were pleasantly surprised when New York Time's bestselling author and Wake Forest University alumna, Emily Giffin, commented on the post.

Soon after Dr. Shirey's opening remarks, students collected their materials and scattered throughout the library to begin their writing process. Program coordinators observed students setting up in a variety of different library spaces, including private study rooms, comfortable reading chairs, and collaborative work spaces. 


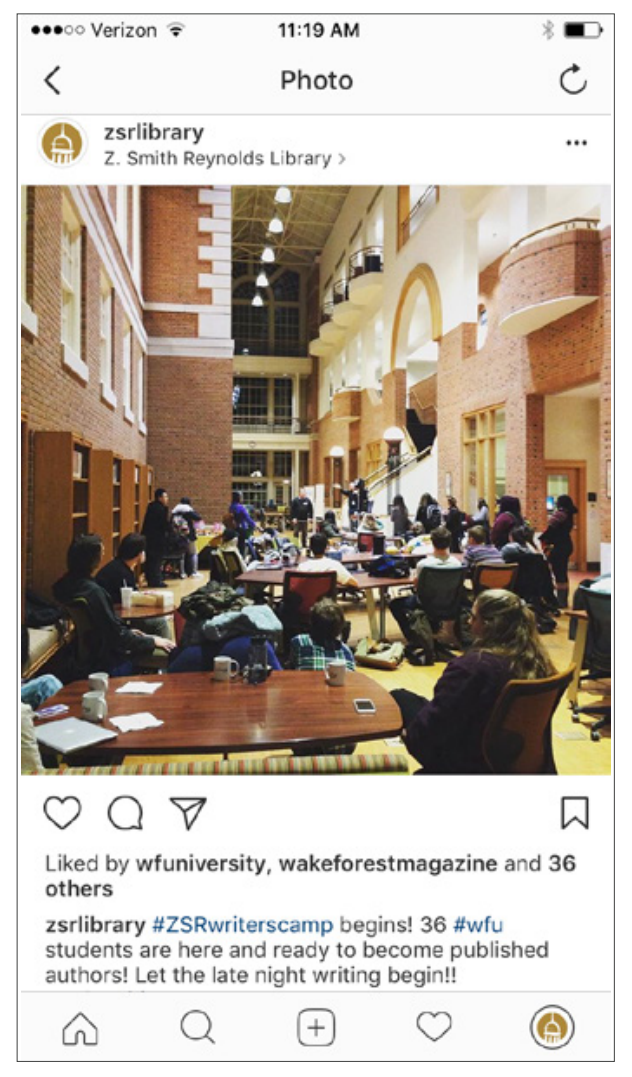

Writers Camp Instagram post

Occasionally, student writers would return to the Library's Atrium for a coffee or snack refill, to ask a question or share an idea with a program coordinator or one of the Writing Center tutors, and/or to take a quick break from writing to recharge and commiserate with friends. At midnight, a pizza break was provided by the Office of Personal and Career Development and student writers were invited back to the Atrium.

As the evening progressed, editorial requests and activity with the Writing Center tutors began to pick up around midnight through 2:00 am. Several student writers took advantage of having their work proofed at different stages of their writing process.

While some students continued their writing throughout the entire duration of the event, about half of the participants chose to leave the event after they had completed their work, with plans to return for the celebratory biscuit breakfast to close the event.

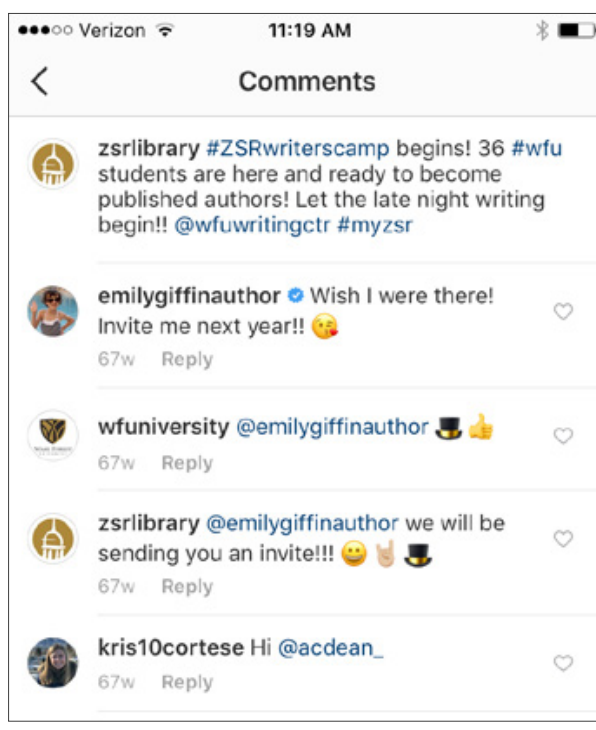

The event was shared on ZSR Library's social media channels and committee members were pleasantly surprised to see WFU Alumna and New York Times best-selling author Emily Giffin comment on the event.

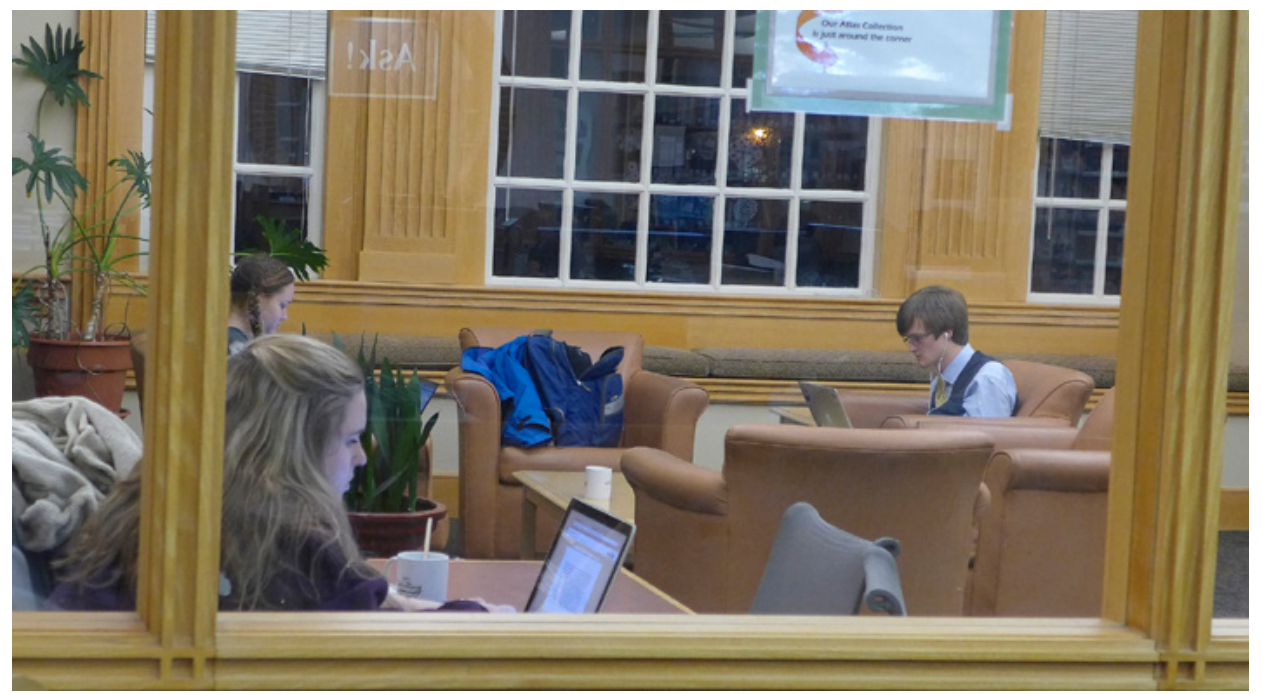

These student authors enjoyed being in the company of other writers while they worked throughout the evening.

Although students were encouraged to continue writing throughout the evening, they were allowed time after the end of the event to continue working on their pieces before final submissions would be due.

\section{After the Event}

Once the event had concluded, the work began in haste for post-production of the student writing. Writers Camp Committee members were asked to read the completed student work

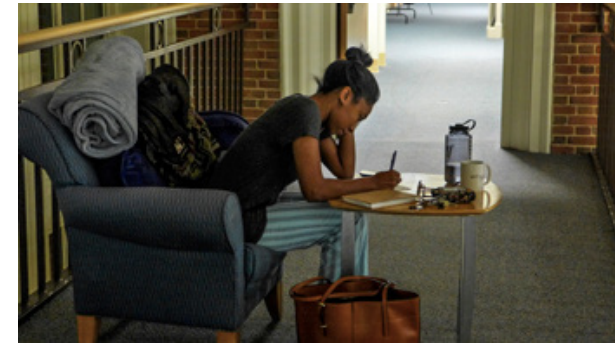

A Writers Camp author hard at work, writing late into the evening.

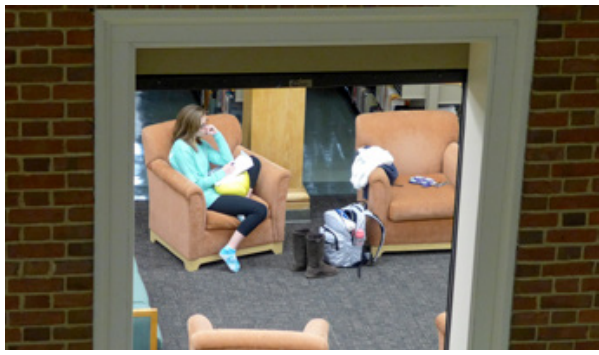

Setting up camp in the Reynolds wing! A student author sets up for a long night of writing. 
University academic leaders, including the Dean of the Library, Associate Provost, and the Associate Dean/Director of the Wake Forest Scholars Program. In keeping with our professional values of librarianship (as outlined in ALA's Library Bill of Rights) promoting intellectual freedom and challenging censorship of artistic license, the Writers Camp Committee decided to keep the work intact, in its original form, and include a brief trigger warning to alert readers to the content, in case they wished to avoid engaging with the text.

To gauge feedback from the student writers, a post-event survey was created and shared. From the event survey, 19 of the 34 student participants reported:

- An overall satisfaction with the Writers Camp program (63\% of respondents reporting a high satisfaction with the program)

- Meeting the goal of engaging students in "a fun and scholarly event" ( $84 \%$ of student respondents)

- Meeting the goal of showcasing ZSR Library Special Collections and Archives (94\% of student respondents)

- A recommendation to involve student writers in the final editing processes before publication of their work

- A recommendation to make spending the night in the library optional (which it was)

- The special collections artifact prompts were unnecessarily limiting to their creative process (even though they were optional)

A call was made to all Writers Camp participants and committee members to submit proposals for the title of the Writers Camp publication and the title, Wake the Artifacts: Student Writing from Wake Forest University's Special Collections was chosen.
Finally, once the complete draft was finalized, the Writers Camp Committee worked with the ZSR Library's Special Collections department to make "special editions", and the book was added to the library's rare books collection. Records for the print and electronic book versions were uploaded to OCLC and the ZSR Library's online catalog. Library Partner's Press provided print copies for each Writers Camp participant and committee member.

\section{Lessons Learned}

The Library plans to leverage what was learned from the first event to both streamline and improve Writers Camp @ ZSR 2018. By using the ADDIE Model: Analysis, Design, Development, Implementation, and Evaluation, the library identified elements of the original project that were extraneous. Survey responses revealed that an opening ceremony, programmed writing breaks, and "schwag" or gift bags are not valued by the students, but assistance from the Writing Center tutors late in the evening, a branded coffee mug, and a print copy of the book were all highly valued. Additionally, these writers didn't need the brainstorming exercises or distractions we had planned for them. They were there to write!

As the Library determines the elements students valued most, staffing for the event can also be improved and streamlined. Many staff arrived early on the day of the event, preparing for both the event and the opening reception, then stayed overnight, working almost 24 hours. By removing the opening reception, and dividing up duties, staff working the overnight portion of the event can come in later and those working the opening of the event can leave earlier in the evening, reducing both the number of staff needed, and reducing the number of hours worked.
The 2016 event was $\$ 1000$ under budget, and by removing costs students didn't find valuable, another $\$ 2500$ will be cut from the budget for 2018 . Finding funding for a $\$ 1000$ event will prove easier than funding a $\$ 4500$ event. Funding continues to be an ongoing challenge, and long range plans include finding a permanent source of recurring funding for this biennial event. The Library's development officer is working on a crowdfunding approach to raise these funds. Leveraging the student feedback received from the post-event survey will allow the librarians to design an even more successful event for 2018 .

\section{The Next Chapter}

As Writers Camp concluded, and the books were distributed and the surveys were reviewed, the Library realized this event could be the first step in creating a community of student writers, with the Library as their hub. Writers Camp has led to a series of other outreach events at the ZSR Library that focus on student writing outside of the classroom. In addition to making Writers Camp a biennial event, the Library has also started hosting events during National Novel Writing Month, branded as "WaFoWriMo" where many of the same students who participated in Writers Camp can return to ZSR and work on their personal writing projects while getting support from the University Writing Center. Additionally, the Library has hosted the first of what will be a series of Wikipedia-Edit-aThons called "Writing Stories, Righting History." where students can edit or create Wikipedia entries for members of groups underrepresented on Wikipedia.

What began as an idea shared between colleagues at an ALA Annual Conference keynote presentation flourished into a unique programming 
opportunity at an academic library to offer students the chance to become published authors. Writers Camp is a special example of outreach in ZSR's culture. The addition of academically engaging events to ZSR's repertoire of outreach aligns with one of the University's goals to foster an academic community, and increase academic engagement outside of the classroom. To meet this goal, a community of campus partners, across disciplines was essential to move the project forward. Also required was a culture of innovation-- a willingness to embrace new opportunities without fear of failure.

The program coordinators were pleasantly surprised with the number of engaged participants and the level of enthusiasm for this student program. This experience confirmed the presence of a group of active, diverse student writers on campus who benefit from creative programming, support and encouragement for their literary pursuits outside of the classroom. From the solicited feedback, student participants applauded the program's value and expressed a need for continuing opportunities to cultivate a network of student writers. In that spirit, Writers Camp has inspired a series of continuing programs for student writers on campus.

Writing is often seen as a solitary activity, and this event allowed solopractitioners to find a community of like-minded artists. This experience has reminded us once again of the transformative power of libraries to foster creativity and artistic inspiration, while building communities of practice.

\section{References}

American Library Association. (2010, "Assessment in Action -- Final Report." https://zsr.wfu.edu/about/administration/assessment/assessment-in-action/. "Digital Fun: Find the Future: The Game." http://exhibitions.nypl.org/100/ digital_fun/play_the_game.

"Historical Visitation Statistics 19702016." https://www.lvcva.com/statsand-facts/visitor-statistics/.

"Past Annual Conferences." http://www. ala.org/conferencesevents/past.

Burris, Christian, Carolyn McCallum, and Molly Keener. "Incorporating Branded Academic Library Programming to Promote and Showcase Campus Research and Artistic Performances." North Carolina Libraries 74, no. 1 (2016): 13.

Womack, Hubert, Susan Smith, and Mary Lock. "Large-Scale, Live-Action Gaming Events in Academic Libraries." College \& Research Libraries News 76, no. 4 (2015): 210.
Womack, Hubert David. "ALA 2014 According to $\mathrm{Hu} . .$. . (I Can't Think of a Catchy Title for This.)." https://zsr. wfu.edu/inside/2014/ala-2014-according-to-hu-i-cant-think-of-a-catchytitle-for-this/.

\section{Hubert Womack}

Instruction and Outreach Librarian, Z. Smith Reynolds Library, Wake Forest University

\section{Carolyn McCallum}

Cataloging Librarian for Nonprint Materials, Z. Smith Reynolds Library, Wake Forest University

\section{Meghan Webb}

Instruction and Outreach Librarian, Z. Smith Reynolds Library, Wake Forest University

\section{North Carolina Libraries}

Official Publication of the North Carolina Library Association

ISSN 0029-2540

All issues are available online free-of-charge at http://www.ncl.ecu.edu.

Back issues are available from the North Carolina Library Association office at 1811 Capital Blvd., Raleigh, NC 27604 , for $\$ 8$ an issue for those years prior to going online in 2002 , or $\$ 50$ for the annual print compilation beginning with Vol. 60 (2002). 